


\title{
IMPLEMENTASI MANAJEMEN BERBASIS SEKOLAH (MBS) DALAM \\ MEWUJUDKAN SEKOLAH MANDIRI DI SD MUHAMMADIYAH \\ KARANGKAJEN YOGYAKARTA
}

\author{
Nurhidayah
}

Universitas Ahmad Dahlan Yogyakarta

Email: Nur.hidayah@pgsd.uad.ac.id

\begin{abstract}
ABSTRAK
Penelitian ini bertujuan untuk 1) Mengetahui kepemimpinan kepala sekolah di SD Muh Karangkajen, 2) Mengetahui iklim sekolah di SD Muh Karangkajen, 3) Mengetahui otonomi sekolah di SD Muh Karangkajen.

Jenis penelitian ini adalah deskripsi secara kualitatif. Data primer diperoleh melalui wawancara, studi pustaka, dokumentasi dan observasi tentang implementasi MBS di SD Muh Karangkajen. Narasumber ditetapkan dengan metode purposive sampling. Objek penelitian adalah SD Muh Karangkajen dan subjek penelitian adalah seluruh warga sekolah dan masyarakat. Teknik analisis data memakai metode induktif dan komparatif.

Hasil penelitian menunjukkan bahwa: a) Manajemen berbasis sekolah di SD Muhammadiyah Karangkajen memiliki karakteristikyang khusus di antaranya yaitu kepemimpinan sekolah yang dalam bertindak/ menjalankan tugas kepala Sekolah di SD Muh Karangkajen bertindak sangat arif, bijaksana, adil dan visioner; dalam pengoptimalan pelaksanaan kultur sekolah di antaranya adalah penanaman budaya disiplin; pelaksanaan kegiatan keagamaan secara rutin, pelaksanaan pembelajaran Aktif, Kreatif, Efektif dan Menyenangkan (PAKEM); Upaya sekolah dalam melaksanakan otonomi sekolah di antaranya adalah manajemen tenaga pendidik, manajemen siswa, manajemen kurikulum. b) Manajemen Berbasis Sekolah yang ada di SD Muh Karangkajen dapat membangun standar kompetensi guru, pengembangan kurikulum melalui pembelajaran yang aktif, kreatif, dan menyenangkan. c) Pelaksanaan manajemen berbasis sekolah di SD Muhammadiyah Karangkajen merupakan langkah pengelola sekolah dalam membangun kemandirian dalam beberapa bidang, yaitu bidang pengadaan tenaga kependidikan, pengembangan kurikulum sekolah.
\end{abstract}

Kata kunci: Implementasi, Managemen Berbasis Sekolah, Sekolah Mandiri

AL-BIDAYAH: Jurnal Pendidikan Dasar Islam Volume 9, Nomor 1, Juni 2017; ISSN: 2085-0034 


\begin{abstract}
This study aims to 1) Know the leadership of the principal in SD Muh Karangkajen, 2) Know the school climate in SD Muh Karangkajen, 3) Knowing the school's autonomy in SD Muh Karangkajen.

This type of research is qualitative description. Primary data obtained through interview, literature study, documentation and observation about the implementation of school based management (SBM) in SD Muh Karangkajen. The informant is determined by purposive sampling method. The object of research is SD Muh Karangkajen and the subject of research is all citizens of the school and community. Data analysis techniques use inductive and comparative methods.

The results of the study show that: a) School-based management in Muhammadiyah Karangkajen elementary school has special characteristics such as school leadership in performing the tasks of the principal in SD Muh Karangkajen acting very wise, fair, and visionary; In optimizing the implementation of school culture among them is the cultural cultivation of discipline; The implementation of religious activities on a regular basis, the implementation of Active, Creative, Effective, and Enjoyable learning (ACEEL); School efforts in implementing school autonomy include the management of educators, student management, curriculum management. b) School Based Management in Muh Karangkajen Primary School can build teacher competency standard, curriculum development through active, creative, and fun learning. c) Implementation of school-based management in SD Muhammadiyah Karangkajen is a step school managers in building independence in several areas, namely the field of procurement of educational personnel, development of school curriculum.
\end{abstract}

\title{
Keywords: Implementation, School Based Management, Independent School
}

\section{A. PENDAHULUAN}

Reformasi pendidikan ditujukan untuk meningkatkan komitmen dan kemampuan guru dan murid untuk mencapai prestasi pendidikan sebagaimana diharapkan. Dengan reformasi pendidikan dimaksudkan untuk mengembangkan struktur dan kondisi yang memungkinkan munculnya komitmen dan kemampuan tersebut. Oleh karena itu, reformasi yang dilakukan harus mencakup tiga aspek dalam pendidikan: aspek organisasi dan kultur sekolah, aspek pekerjaan guru, dan aspek interaksi sekolah dan masyarakat.
Kekuatan reformasi yang hakiki sebenarnya bersumber dari sumber daya manusia yang berkualitas, memiliki visi transparansi dan pandangan jauh ke depan. Peningkatan kualitas sumber daya manusia merupakan syarat untuk mencapai tujuan pembangunan. Salah satu wahana untuk meningkatkan kualitas sumber daya manusia tersebut adalah melalui pendidikan. Pendidikan memberikan kontribusi yang sangat besar untuk kemajuan suatu bangsa.

Era reformasi ditandai dengan beberapa perubahan dalam berbagai bidang kehidupan, politik, moneter dan beberapa kebijakan 
mendasar lainnya. Perubahan tersebut diantaranya lahirnya undang-undang No 22 tahun 1999 tentang otonomi daerah. Undangundang ini berisi tentang kewenangan daerah sehingga lebih otonom, termasuk di bidang pendidikan.

Pengelolaan pendidikan yang semula diatur secara terpusat/ sentralisasi, sejak diundangkannya UU no 22 tahun 1999 maka pengelolaan pendidikan secara otonomi dan desentralisasi, dimana pengelolaan ini salah satunya menuntut partisipasi masyarakat secara aktif untuk merealisasikan otonomi daerah. Di dunia pendidikan pengelolaan manajemen sekolah secara otonomi dan desentralisasi ini disebut dengan manajemen berbasis sekolah. Pemberian otonomi yang lebih luas kepada sekolah dimaksudkan untuk meningkatkan mutu pendidikan secara umum.

Sekolah adalah refleksi dari sebuah masyarakat kecil, yang menjadi wahana pengembangan siswa, bukan agensi birokrasi yang sarat beban administrasi. Sejalan dengan arah kebijakan otonomi dan desentralisasi yang ditempuh pemerintah, tanggung jawab pemerintah daerah akan meningkat termasuk dalam pengelolaan manajemen pendidikan di sekolah. Dominasi birokrasi dan kontrol politik yang berlebih-lebihan dari pusat atas sekolah dan proses belajar-mengajar melahirkan organisasi dan kultur sekolah yang tidak mendukung proses pendidikan yang mampu menghasilkan lulusan yang berkualitas.

Fakta yang ada di lapangan menunjukkan banyak pengelola sekolah hanya menunggu instruksi dari atasan untuk segala urusan. Bila tiada petunjuk pelaksanaan dan petunjuk teknis, mereka enggan melakukan improvisasi di bidang pengembangan pendidikan termasuk kurikulum, administrasi sekolah, model pembelajaran, evaluasi hingga manajemen sekolah. Fakta ini bukan hanya terjadi di sekolah-sekolah umum negeri tetapi juga sekolah-sekolah swasta, termasuk sekolahsekolah Muhammadiyah. Persepsi keliru ini mesti dikoreksi sebab berpotensi memperburuk citra sekolah sebagai tempat pendidikan dan pemberdayaan insan - insan yang bertakwa, unggul, berkarakter, dan berdaya guna.

Saat ini, sebagian masyarakat menilai sekolah Muhammadiyah kurang kreatif dan inovatif sehingga kalah bersaing dengan sekolah-sekolah lain. Pengelola sekolah yang sudah mau pensiun, terlalu mengandalkan pasokan tenaga dari pemerintah, kemandirian sekolah yang melemah, dan isu-isu lain adalah suara yang kerap beredar di tengah masyarakat.

Kondisi ini berimbas animo masyarakat untuk menyekolahkan anak-anaknya di sekolah Muhammadiyah. Selain itu rendahnya mutu pendidikan, kurangnya disiplin, kurangnya kepercayaan masyarakat, minimnya sarana dan prasarana pendukung pendidikan, kurang profesional dan berkarakternya tenaga pendidikan, persoalan yayasan, permasalahan keuangan dan berbagai alasan lain adalah beberapa faktor yang ikut memperburuk kondisi.

Padahal di lain sisi, sekolah Muhammadiyah merupakan institusi pendidikan yang bernilai penting dalam ihwal pendidikan generasi muda Indonesia. Nilai penting Muhammadiyah sebagai institusi pendidikan adalah materi, bobot dan jumlah pendidikan Islam dalam kurikulum pendidikannya. Nilai penting ini sangat berkaitan erat dengan jumlah penduduk Indonesia yang mayoritas Muslim.

Untuk kemajuan pendidikan ke depan, tentu saja menjadi pertanyaan dan persoalan mendasar/ pokok bagaimana menciptakan 
sebuah sekolah mandiri ala Muhammadiyah yang sarat prestasi dan reputasi yang meramukan segala kemadirian, keterbatasan, kemajemukan dan kompleksitas yang ada demi mencetak generasi muda yang bertakwa, unggul, berkarakter (akhlaqul karimah) dan bermanfaat.

Pemberian otonomi yang lebih luas menuntut pendekatan manajemen yang lebih kondusif di sekolah agar dapat mengakomodasi seluruh keinginan sekaligus memberdayakan berbagai komponen masyarakat secara efektif, guna mendukung kemajuan dan sistem yang ada di sekolah. Dalam kerangka desentralisasi sekolah ini, Manajemen Berbasis Sekolah (MBS) tampil sebagai paradigma baru dalam pengelolaan manajemen sekolah. MBS merupakan suatu konsep yang menawarkan otonomi pada sekolah untuk menentukan kebijakan sekolah dalam rangka meningkatkan mutu, efisiensi dan pemerataan pendidikan agar dapat mengakomodasi keinginan masyarakat setempat serta menjalin kerja sama yang erat antara sekolah, masyarakat, dan pemerintah.

Ada banyak padanan kata dari konsep MBS di dunia dengan berbagai variannya. Di Indonesia, konsep MBS lebih dikenal dan sering dipertukarkan dengan konsep Manajemen Peningkatan Mutu Berbasis Sekolah (MPMBS). Konsep MBS diperkenalkan seiring era desentralisasi pendidikan dan diiringi alasan demi meningkatkan kualitas pendidikan nasonal. Terlebih, sejak tahun 2009 pemerintah berkomitmen mencanangkan program wajib belajar pendidikan dasar 9 tahun dan memenuhi amanat UUD 1945 untuk mengoptimalkan anggaran pendidikan nasional sebesar $20 \%$ dari APBN. Persoalannya, bagaimana MBS sebagai sebuah tren di dunia pendidikan bisa diterapkan di sekolah-sekolah Muhammadiyah dengan misi menciptakan sekolah mandiri dengan mengingat fakta dan kompleksitas kemajemukan yang ada di Indonesia. Selain itu rintisan sekolah mandiri Muhammadiyah juga menjadi model dalam implementasi manajemen berbasis sekolah.

Wacana sekolah mandiri mengemuka sejak periode Muktamar 1995-2000, saat era Amien Rais memimpin, bergulir hingga kini. Dalam salah satu butir rekomendasi Majelis Dikdasmen Pimpinan Pusat Muhammadiyah, tercantum alasan mengapa sekolah mandiri mendesak di lingkungan Muhammadiyah. Butir rekomendasi ini berbunyi, "mengingat akhirakhir ini sangat ramai dibicarakan masalah sekolah mandiri, yang menandakan ada ketidakpuasan sebagian masyarakat terhadap kualitas sekolah (termasuk sekolah-sekolah dasar Muhammadiyah) yang ada sekarang ini, karena apa yang ditawarkan dan diberikan oleh sekolah tidak sesuai dengan yang mereka harapkan". PP Muhammadiyah sendiri terlihat sangat antusias dan serius menangani masalah ini. Beberapa kali PP Muhammadiyah majelis Dikdasmen memfasilitasi pertemuan para kepala sekolah dalam rangka merumuskan format ideal sekolah mandiri Muhammadiyah, seperti pertemuan di Yogyakarta Maret 2004 dan tanggal 20-22 Agustus 2004 di Surabaya. Menyongsong Muktamar Muhammadiyah di Malang, PPMuhammadiyah Majelis Dikdasmen menggelar Olimpiade Matematika khusus bagi SD/MI Muhammadiyah se-Indonesia untuk memotivasi pengembangan sekolah-sekolah mandiri Muhammadiyah terutama di mata pelajaran Sains dan Matematika.

Secara normatif, rumusan sekolah mandiri Muhammadiyah memiliki tolak ukur: 1) tertib ibadah (al-Islam), 2) mahir baca tulis Alqur'an, 3) berwawasan kebangsaan, 4) 
pengetahuan akademis tinggi, 5) keterampilan berbahasa asing, 6) keterampilan komputer. Dalam implementasinya, banyak permasalahan mengemuka, seperti belum ada titik temu tentang bagaimana wajah sekolah mandiri itu. Terlepas dari itu semua, rumusan ideal mengenai sekolah mandiri yang bersifat menyeluruh dan tunggal memang tidak begitu dibutuhkan, mengingat pluralitas masyarakat Indonesia meskipun Muslim.

Enam kriteria normatif mesti diterjemahkan sesuai dengan keadaan masyarakat dan kebutuhan stakeholders setempat. Kelak, ini akan melahirkan model-model sekolah mandiri yang sangat heterogen dan bervariasi. Jelasnya, sekolah di dekat pantai berbeda dengan sekolah di pegunungan, sekolah di kota tidak sama dengan sekolah di pedesaan, meskipun samasama sekolah mandiri Muhammadiyah. Jadi wajah sekolah mandiri ala Muhammadiyah beragam sesuai dengan budaya, geografi, dan demografi setempat.

Di sisi lain, Pengelola pendidikan dasar Muhammadiyah dituntut agar menciptakan kondisi sekolah dasar Muhammadiyah menjadi sekolah yang mandiri. Sekolah mandiri unggul dalam manajemen sekolah, pengembangan kurikulum, improvisasi metode pembelajaran, perbaikan evaluasi, pengadaan tenaga pendidik dan non kependidikan, penggalian dana, peningkatan sarana dan prasarana, peningkatan mutu akademis, kedisiplinan civitas akademik, peningkatan SDM ataupun hal ihwal lain. Tuntutan ini menyiratkan tantangan, peluang dan prospek yang bisa diatasi dan dioptimalkan demi kemajuan Muhammadiyah sendiri sebagai organisasi sosial kemasyarakatan maupun institusi pendidikan.

Salah satu solusi untuk mewujudkan sekolah mandiri adalah dengan memanfaatkan terobosan-terobosan yang berkaitan erat dengan konsep dan program sekolah mandiri, seperti manajemen berbasis sekolah. Bagaimana memanejemen sekolah menjadi institusi mandiri mengacu sekolah itu sendiri, adalah menjadi persoalan penting.

Banyak Sekolah Dasar Muhammadiyah telah menerapkan MBS. Sekolah-sekolah ini dikelola secara profesioonal, mempunyai kemandirianyangbaik,mampumengembangkan kurikulum, mempunyai evaluasi komprehensif, mempunyai budaya mutu yang tinggi. Sekolahsekolah Muhammadiyah yang dikelola seperti ini di mata masyarakat menjadi sekolah mandiri dan diminati. Buktinya, animo siswa baru selalu melebihi jumlah kursi penerimaan. Salah satunya di SD Muhammadiyah Karangkajen. Dengan sekitar 1000 siswa dan 50 tenaga pendidik dan non kependidikan, SD ini mampu meraih banyak prestasi.

Citra dan reputasi SD Muhammadiyah Karangkajen sendiri relatif bagus di mata masyarakat sekitar. Ini terbukti dari animo pendaftaran siswa, harapan dan kepercayaan masyarakat seputar pendidikan anak yang terjamin di sana, prestasi, biaya yang terjangkau dan kelengkapan fasilitas. Sekolah ini sudah menerapkan sistem MBS dengan penyesuaian dan pengembangan psikologi islami.

Kepemimpinan di SD Muhammadiyah Karangkajen juga berjalan dengan demokratis, hal ini berkaitan dengan masalah kepala sekolah dalam meningkatkan kesempatan untuk mengadakan pertemuan secara efektif dengan para guru dalam situasi yang kondusif. Perilaku kepala sekolah juga dapat memotivasi kinerja para guru dengan menunjukkan rasa bersahabat, dekat, dan penuh pertimbangan terhadap para guru baik secara individu ataupun dalam institusi. 


\section{B. METODE PENELITIAN}

Jenis penelitian ini adalah deskripsi secara kualitatif. Deskripsi adalah representasi objektif mengenai fenomena yang ditelaah. Sebelum menelaah, peneliti terlebih dahulu harus mempunyai satu cara berpikir dan mengupas, dengan referensi atau titik tolak tertentu. Analisis dengan deskripsi kualitatif dilakukan dengan menghimpun data sewajarnya, menggunakan cara kerja yang sistematis, terarah dan bisa dipertanggungjawabkan secara ilmiah. Deskripsi bermaksud menghimpun informasi aktual secara rinci yang melukiskan gejala yang ada, mengidentifkasi masalah atau memeriksa kondisi dan praktik-praktik yang berlaku, membuat perbandingan atau evaluasi, menentukan apa yang dilakukan dan menghadapi masalah yang sama dan belajar dari pengalaman untuk menetapkan rencana dan keputusan di waktu mendatang. (Isaac dan Michael dalam Rahmat, 2004: 34-35).

Penelitian deskriptif bertujuan untuk menggambarkan suatu keadaan atau status fenomena. Jadi, penelitian deskriptif berusaha memaparkan data sebagaimana adanya tanpa membuat suatu perbandingan atau korelasi antar banyak variabel riset yang ada. Dalam penelitian deskriptif, data kualitatif dan kuantitatif bisa dipakai. Dengan begitu, riset deskriptif dapat diarahkan ke satu dari keduanya (Arikunto, 2007: 29).

Peneliti akan menggunakan wawancara, dokumentasi, dan observasi untuk menghimpun data. Sumber-sumber data primer dan sekunder akan dihimpun, kemudian diedit, ditelaah, dan disajikan dengan prosedur tertentu guna menghadirkan laporan penelitian yang komprehensif, mendalam, dan tuntas. Teknik penelitian yang dipakai adalah survei sebagai studi pendahuluan dan studi kasus di SD Muhamadiyah Karangkajen.
Wawancara dilakukan kepada narasumber sebanyak lima orang dengan teknik purposive sampling. Artinya, dari sekian banyak populasi penelitian, peneliti menentukan sampel penelitian untuk menghimpun data melalui wawancara berdasarkan pertimbanganpertimbangan tertentu.

Populasi penelitian mencakup seluruh elemen civitas akademika diSD Muhammadiyah Karangkajen yang terdiri dari kepala sekolah koordinator urusan tertentu yang berfungsi sebagai wakil kepala sekolah, koordinator kelas, karyawan.

\section{HASIL DAN PEMBAHASAN}

\section{Kepemimpinan Kepala Sekolah}

Kepala sekolah sebagai seorang pemimpin selalu memperhatikan dan mempraktikkan fungsi kepemimpinan dalam kehidupan sehari-hari di sekolah diantaranya:

1) Dalam bertindak/ menjalankan tugas kepala Sekolah di SD Muh Karangkajen bertindak sangat arif, bijaksana, adil, tidak ada pihak dikalahkan atau dianakemaskan.

2) Kepemimpinan kepala sekolah yang lain

a) Membuat klub jemparingan untuk ekstra panahan yang diikuti kelas 3-6, dimana ekstra jemparingan ini menjadi kewirausahaannya kepala sekolah termasuk guru.

b) Membuat kelas hafalan/ tahfidz Alqur'an

c) Membuat kelas olah raga

d) Menambah ekstra kurikuler siswa yaitu angklung.

Menurut Bapak Suhardi alasan-alasan implementasi MBS di SD Muh Karangkajen adalah: 
1) Otonomi lebih besar kepada sekolah yang berarti sekolah lebih kreatif dalam peningkatan mutu sekolah

2) Sekolah lebih besar mengelola sumber daya, berarti sekolah lebih lincah dalam pengadaan dan pemanfaatan sumber daya sekolah secara optimal demi menigkatkan mutu sekolah

3) Sekolah lebih mengetahui kekuatan, kelemahan, peluang, dan ancaman (Analisis SWOT) bagi dirinya sehingga bisa memanfaatkan sumberdaya yang tersedia untuk memajukan sekolahnya

4) Sekolah lebih mengetahui kebutuhan lembaganya, khususnya input pendidikan yang akan dikembangkan dan didayagunakan dalam proses pendidikan sesuai dengan tingkat perkembangan dan kebutuhan

5) Keterlibatan semua warga dan masyarakat dalam pengambilan keputusan sekolah menciptakan transparansi dan demokrasi yang sehat

6) Sekolah dapat bertanggung jawab tentang mutu pendidikan kepada pemerintah, orang tua/ wali dan masyarakat umum sehingga dapat melaksanakan dan mencapai sasaran mutu

7) Sekolah dapat melakukan persaingan sehat dengan sekolah lain.

Karakteristik MBS tidak dapat dipisahkan dengan karakteristik sekolah mandiri. Jika MBS adalah wadah atau kerangkanya, maka sekolah mandiri adalah isinya. Karakteristik MBS memuat secara inklusif elemen-elemen sekolah efektif yang terbagi menjadi input, proses, dan output. Artinya, dengan pendekatan sistem, SD Muh Karangkajen lebih dilihat sebagai sebuah sistem yang unsur-unsurnya menjadi subsistem. Seluruh subsistem saling berkaitan dan berfungsi bersama, masingmasing saling menopang dan melemahkan. Bila satu sistem tidak bekerja, maka subsistem yang lain akan terpengaruh dan berakibat buruk pada SD Muh karangkajen secara keseluruhan.

Berdasarkan beberapa teori dan observasi maupun wawancara, peneliti menyimpulkan bahwa MBS adalah sebuah model yang memberi otonomi luas kepada para pengelola sekolah (Kepala sekolah, guru, karyawan/ TU) dalam mendorong peran serta masyarakat secara langsung dalam pengembangan dan peningkatan mutu sekolah. Masyarakat termasuk orang tua siswa, tokoh masyarakat, ilmuwan bersama-sama meningkatkan mutu sekolah berdasarkan kebijakan nasional serta peraturan perundang-undangan yang berlaku.

\section{Kultur sekolah}

\section{a. Budaya Disiplin}

Variabel budaya disiplin merupakan variabel kedua yang mendukung implementasi MBS di SD Muh Karangkajen menuju kemandirian sekolah. Budaya disiplin kerja, disiplin siswa, disiplin beribadah, disiplin sekolah, iklim kerja adalah atmosfer kekeluargaan yang terbina dengan baik, tidak adanya diskriminasi, transparansi dalam hal sistem penggajian, tunjangan, dan kesejahteraan, partisipasi yang aktif dari warga sekolah adalah bukti-bukti otentiknya.

SD Muh Karangkajen juga memberlakukan budaya disiplin sekolah yang berlaku bagi seluruh warga sekolah. 
Budaya disiplin itu meliputi

1) Berseragam sekolah sesuai jadwal seragam sekolah yang berlaku

2) Masuk maksimal 06.20 WIB pulang pukul 13.30 WIB (kecuali guru, karyawan piket masuk sebelum 06.00 dan pulang setelah pukul 14.30)

3) Mengerjakan tugas administrasi dan pengawasan kepada siswa selama jam pelajaran maupun di luar pelajaran

4) Menyerahkan Rencana Pokok Pembelajaran/ RPP setiap minggu dan disetujui koordinator KBM/ Kepala Sekolah

5) Menyusun silabus pelajaran per semester

6) Melakukan pembinaan afektif pada siswa di luar jam pelajaran.

Disiplin siswa meliputi:

1) Berseragam rapi sesuai ketentuan sekolah (setiap hari seragam berbeda/ berganti termasuk olahraga)

2) Masuk paling lambat $06.30 \mathrm{WIB}$

3) Larangan jajan di luar selama jam istirahat, demi menjaga kesehatan, sekolah juga menyediakan kantin sekolah yang menyediakan jajanan sehat dan bergizi bagi siswa-siswinya

4) Kewajiban menjalankan ibadah shalat dan tadarus setiap hari.

\section{b. Kegiatan Keagamaan}

Budaya sekolah islami dibangun melalui usaha-usaha diantaranya adalah

1) Pengajian ahad pagi

2) Pesantren ramadhan

3) Program membaca Alquran bagi semua siswa
4) Sholat sunah Dluha

5) Sholat Dhuhur berjamah yang dilaksanakan waktu istirahat kedua

6) Pembagian zakat fitrah dan qurban kepada masyarakat sekitar SD yang berhak menerima.

\section{Pembelajaran Aktif, Kreatif, Efektif, dan Menyenangkan (PAKEM).}

Proses pembelajaran di sekolah jauh lebih rumit dibandingkan proses produksi di pabrik. Untuk menjamin keberhasilan proses pembelajaran maka proses KBM di kelas dirancang agar anak bisa aktif, kreativitas mereka berkembang sehingga efektif namun tetap menyenangkan. Proses pembelajaran berkaitan dengan proses memandirikan seorang anak manusia agar bisa belajar sendiri dalam menghadapi hidupnya kelak.

PAKEM adalah singkatan dari Pembelajaran Aktif, Kreatif, Efektif, dan Menyenangkan. Aktif berarti guru harus menciptakan suasana sedemikian rupa sehingga siswa aktif bertanya, mempertanyakan dan mengemukakan gagasan dalam proses pembelajaran. Belajar merupakan proses aktif dari si pembelajar (learners) dalam membangun pengetahuannya dan menambah stok pengetahuannya. Partisipasi aktif siswa amat penting dalam pembentukan generasi kreatif, yang mampu menghasilkan sesuatu bagi kepentingan dirinya dan sesama. Kreatif berarti guru menciptakan beragam kegiatan belajar yang mampu memenuhi berbagai kadar kemampuan siswa. Menyenangkan adalah suasana KBM yang mengasyikkan sehingga siswa memusatkan perhatiannya secara penuh pada belajar sehingga "time on task" mereka tinggi. Menurut hasil penelitian, tingginya waktu curah studi 
terbukti meningkatkan hasil belajar. Keadaan aktif dan menyenangkan tidaklah cukup. Proses pembelajaran harus efektif, yaitu menghasilkan apa yang harus dikuasai siswa usai proses pembelajaran berlangsung. Pembelajaran mensyaratkan sejumlah tujuan pembelajaran yang harus dicapai.

Tabel 1. PAKEM menurut sisi guru dan siswa e. Mengembangkan kelas sebagai lingkungan belajar yang menarik

f. Memanfaatkan lingkungan sebagai sumber belajar

g. Memberi umpan balik yang baik untuk meningkatkan kegiatan belajar

h. Membedakan antara aktif fisik dan aktif mental.

\begin{tabular}{|c|c|c|}
\hline PAKEM & GURU & SISWA \\
\hline Aktif & $\begin{array}{l}\text { - Memantau kegiatan belajar siswa } \\
\text { - Memberi umpan balik } \\
\text { - Mengajukan pertanyaan yang } \\
\text { menantang } \\
\text { - Mempertanyakan gagasan siswa }\end{array}$ & $\begin{array}{l}\text { - } \text { Bertanya } \\
\text { - Mengemukakan gagasan } \\
\text { - Mempertanyakan gagasan } \\
\text { orang lain dan gagasannya }\end{array}$ \\
\hline Kreatif & $\begin{array}{l}\text { - Mengembangkan kegiatan belajar } \\
\text { yang beragam } \\
\text { - Membuat alat bantu belajar } \\
\text { sederhana }\end{array}$ & $\begin{array}{l}\text { - Merancang/ membuat sesuatu } \\
\text { - Menulis/mengarang }\end{array}$ \\
\hline Efektif & - Mencapai tujuan pembelajaran & $\begin{array}{l}\text { - Menguasai keterampilan yang } \\
\text { dibutuhkan }\end{array}$ \\
\hline Menyenangkan & $\begin{array}{l}\text { Tidak membuat siswa takut: salah, } \\
\text { ditertawakan, dianggap remeh }\end{array}$ & $\begin{array}{l}\text { - Membuat siswa berani } \\
\text { berbuat/ mencoba, bertanya } \\
\text { mengemukakan gagasan, } \\
\text { mempertanyakan gagasan } \\
\text { orang lain }\end{array}$ \\
\hline
\end{tabular}

Sumber: Data penelitian yang sudah diolah

Dalam implementasi PAKEM, perlu diperhatikan hal-hal berikut:

a. Memahami karakter setiap siswa didik adalah unik dan berbeda

b. Mengenali siswa didik secara perorangan

c. Memanfaatkan perilaku siswa didik dalam pengorganisasian belajar

d. Mengembangkan kemampuan berpikir kritis, kreatif, dan kemampuan memecahkan masalah

\section{Otonomi Sekolah}

Upaya sekolah dalam melaksanakan otonomi sekolah diantaranya adalah manajemen tenaga pendidik, manajemen siswa, manajemen kurikulum, dan lainnya.

Penerapan yang lain adalah dalam melaksanakan pembelajaran yang dilaksanakan secara PAKEM. Meskipun kebijakan pemerintah mengharuskan guru kelas dan tematik untuk kelas 1-3 dan tidak ada guru bidang studi sesuai peraturan, 
namun koordinator Kurikulum SD Muh Karangkajen berpandangan lain. Guru kelas memungkinkan melakukan pembelajaran yang monoton dan tidak sesuai keilmuannya masing-masing. Sehingga dalam MBS ini sekolah mewajibkan pembelajaran PAKEM.

Tolak ukur dan standar tertentu dipatok demi menjaga kualitas yang diharapkan. Tentu saja, inputtersebutharus dikelola dalam sebuah proses yang berkesinambungan, menyeluruh, dan membuahkan hasil. Perekruktan guru harus sesuai standar kompensi tertentu yang memiliki korelasi dengan peningkatan prestasi sekolah dan siswa.

Di sisi lain guru harus mengurusi urusan yang bukan menjadi tugas pokoknya sebagai mengajar. Sebab itulah di SD Muh Karangkajen pekerjaan-pekerjaan lain di luar tugas pokok guru mulai dipisahkan. Sehingga di SD Muh Karangkajen ini ada sejumlah karyawan bidang non kependidikan yang mengurusi administrasi sekolah. Pekerjaan-pekerjaan yang menuntut tenaga-tenaga ahli dan profesional mulai dilimpahkan kepada para pakar di bidangnya. Bila memungkinkan, demi efisiensi dan perampingan manajemen personalia, guruguru tertentu sekaligus mengampu urusanurusan spesifik, seperti guru olah raga menangani unik kesehatan sekolah guru TIK mengelola IT dan laboratorium multimedia sekolah.

Untuk memenuhi kebutuhan guru-guru sesuai dengan standar kompetensi tertentu, maka SD Muh Karangkajen mengadakan seleksi. Adapun materi seleksi mencakup:

a. Administrasi, meliputi kualifikasi ijazah

b. Mempunyai NBM (Nomor Baku Muhammadiyah) c. Tes tertulis 5 materi SD ditambah Bahasa Inggris, Komputer, Agama Islam dan Kemuhamadiyahan

d. Micro Teaching atau praktik mengajar di kelas, yang dinilai guru yang menguji dan siswa

e. Tes wawancara yang yang meliputi loyalitas, ideologi, organisasi Muhammadiyah dan kepemimpinan

Selain itu secara rutin di SD Muh Karangkajen juga melakukan pembinaan dan peningkatan terkait dengan sumber daya (guru), yang meliputi:

a. Program rutin mingguan diantaranya adalah pengembangan keilmuan, pembinaan rohani

b. Program rutin semester sejenis pelatihan/ workshop pada liburan semester

c. Pengajian

d. Pesantren Ramadhan

Dalam manajemen kurikulum di SD Muh Karangkajen membagi menjadi 2, yaitu kegiatan intrakurikuler dan ekstrakurikuler. Intrakurikuler meliputi Pendidikan agama Islam, Bahasa Indonesia, Matematika, IPA, IPS, Penjaskes, Muatan lokal, pendidikan ISMUBA. Ekstrakurikuler mencakup mencakup Seni baca Alquran, Renang, Hizbul Wathan, Tapak Suci, Ekstra mapel, dan lainnya.

\section{KESIMPULAN}

Berdasarkan hasil analisis data dan pembahasan maka dapat diambil kesimpulan sebagai berikut.

1. Manajemen berbasis sekolah di SD Muhammadiyah Karangkajen memiliki karakteristik yang khusus diantaranya yaitu kepemimpinan sekolah yang dalam 
bertindak/ menjalankan tugas kepala Sekolah di SD Muh Karangkajen bertindak sangat arif, bijaksana, adil dan visioner; dalam pengoptimalan pelaksanaan kultur sekolah diantaranya adalah penanaman budaya disiplin, pelaksanaan kegiatan keagaamaan secara rutin, pelaksanaan pembelajaran Aktif, Kreatif, Efektif dan Menyenangkan (PAKEM); Upaya sekolah dalam melaksanakan otonomi sekolah diantaranya adalah manajemen tenaga pendidik, manajemen siswa, manajemen kurikulum

2. Manajemen Berbasis Sekolah yang ada di SD Muh Karangkajen dapat membangun standar kompetensi guru, pengembangan kurikulum melalui pembelajaran yang aktif, kreatif, dan menyenangkan

3. Pelaksanaan manajemen berbasis sekolah di SD Muhammadiyah Karangkajen merupakan langkah pengelola sekolah dalam membangun kemandirian dalam beberapa bidang, yaitu bidang pengadaan tenaga kependidikan dan pengembangan kurikulum sekolah.

\section{E. SARAN}

\section{Bagi pihak sekolah}

a. Sebaiknya SD Muh Karangkajen memiliki divisi-divisi dalam struktur organisasinya. Logika pemisahan akademik dan non akademik harus disertai dengan eliminasi seutuhnya tentang tugas tambahan yang bukan pekerjaan pokok guru. Misalnya, ada tenaga sendiri yang mengurusi perpustakaan, lab komputer, koperasi sekolah.

b. Dalam peningkatan sumber daya guru, jangan hanya mengandalkan workshop rutin saja, tetapi hendaknya juga ada program beasiswa para guru untuk meningkatkan kualifikasi akademiknya secara formal, seperti guru melanjutkan ke jenjang pascasarjana.

\section{Bagi masyarakat}

a. Masyarakat perlu memahami bahwa sekolah swasta seperti SD Muh Karangkajen mempunyai budaya sekolah disiplin yang tinggi, kepemimpinan kepala sekolah yang adil dan visioner.

b. Peran serta masyarakat sangat dibutuhkan, terutama dalam mengontrol, mengawasi, dan mendampingi secara langsung perkembangan sekolah. Semakin solidnya pendampingan masyarakat ke sekolah semakin cepat pula perkembangan sekolah ke arah kemandirian sekolah.

\section{F. DAFTAR PUSTAKA}

Departemen Pendidikan Nasional Direktorat Jenderal Pendidikan Nasional Menengah. 2002, Manajemen Peningkatan Mutu Berbasis Sekolah, Rencana dan Program pelaksanaan Buku 1-4, (Direktorat Sekolah Lanjutan Tingkat Pertama).

Mulyasa. 2007, Manajemen berbasis Sekolah, (Bandung: Remaja Rosdakarya).

Nurkolis, 2005, Manajemen Berbasis Sekolah, (Jakarta: Grasindo).

Slamet P.H. "Manajemen Berbasis Sekolah." Jurnal Pendidikan dan Kebudayaan No 27 Tahun 2001. http://www.pdk.go.id/ jurnal-27/manajemen-berbasis-sekolah. htm

Solikin, Achmad. 2010, Manajemen Berbasis Sekolah(MBS): Sebuah Peluang dan tantangan dalam mengembangkan sekolah mandiri (Studi Kasus di SDMCC) 
Nurhidayah

Suharsimi Arikunto, 2007, Prosedur Penelitian Suatu Pendekatan Praktis, (Yogyakarta: Rineka Cipta).

Sudiono dkk. Menciptakan Masyarakat Peduli Pendidikan Anak Program Manajemen Berbasis Sekolah (MBS): Peningkatan mutu pendidikan dasar melalui Manajemen Berbasis Sekolah dan Peran Serta masyarakat. Paket Pelatihan awal untuk Sekolah dan Masyarakat. (Jakarta: Pemerintah Indonesia, UNESCO, UNICEF dan NZAID).

Undang-undang No 22 tahun 1999 tentang otonomi daerah.

Winarno Surakhmad, Ilmu Kependidikan untuk Pembangunan.

Wahjosumidjo. 2002, Kepemimpinan Kepala Sekolah, (Jakarta: Raja Grafindo).

Zamroni. 2016, Kultur sekolah. (Yogyakarta: Gavin Kalam Utama). 